\title{
Prevention through design in the health care sector
}

\author{
E. Stewart ${ }^{1}$, D. Heidel $^{2}$ \& M. Quinn ${ }^{3}$ \\ ${ }^{1}$ Kaiser Permanente, National Environmental, \\ Health \& Safety Department, USA \\ ${ }^{2}$ National Institute for Occupational Safety and Health, \\ Prevention through Design National Initiative, USA \\ ${ }^{3}$ University of Massachusetts at Lowell, \\ Department of Work Environment, USA
}

\begin{abstract}
The health care sector in the United States traditionally lags behind manufacturing in applying concepts and models that improve process and safety performance. Recently, an initiative to bring risk management systems' thinking to work place process design has started up in the United States, under the guidance of the Center for Disease Control and Prevention's National Institute for Occupational Safety and Health. So called Prevention through Design, it is a broad-based strategic initiative that looks at education, research, policy, and practice through eight market sectors. In health care, Prevention through Design concepts include linkages with sustainability, including green buildings, environmentally-preferable purchasing and ergonomic design, as well as control banding for occupational exposures and patient safety. This paper will present an overview of the Prevention through Design concept and detail specific work that is being done to eliminate work place injuries and illnesses. Examples of successful Prevention through Design efforts at Kaiser Permanente will be highlighted.

Keywords: Prevention through Design, safety by design, health care, worker health and safety, injury prevention, ergonomics, patient safety, sustainability.
\end{abstract}




\section{Root causes of injuries and illnesses}

The United States work force employs about 18 million workers, of which 4.2 injuries per 100 full-time equivalent hours are experienced at work, 1.2 injuries are bad enough to require time away from work (for an average time away of almost one and a half days). Of these people injured and staying away from work, half of them suffer strains, sprains and tears. Compare that to hospitals, which employ roughly 4.4 million workers, but whose recordable case rate is much higher: 7.7 per 100 full-time equivalent hours; and whose injuries are more severe, resulting in a lost time rate of 1.7 and an average time away of almost two days. The most dangerous segment of health care is in caring for the most fragile of the population: nursing home and residential care facility workers. These people suffer debilitating injuries at a rate of 8.8 per 100 full-time equivalent hours, resulting in time away from work rate at 2.6 and staying off the job for two and a half days on average. General medical and surgical hospitals reported more injuries and illnesses than any other industry in 2007 - more than 253,500 cases nationwide. Taken together with ambulatory health care services and nursing care facilities, the total becomes 505,300 cases, accounting for almost 13 percent of the four million cases in total reported in 2007 [1, 2].

To put this in perspective, health care in the United States injures more workers than commercial fishing or construction, both industries which are perceived by the general public to be among the most dangerous professions today. Only transportation (air shipment and couriers and messengers) is more dangerous than health care. As the work force ages, (and American nurses are on average 47 years old, the majority of whom are getting older, not younger; almost half are over the age of fifty)[2], the incidence of career-ending injuries goes up just as the general overall health and fitness of nurses degrades and obesity further hobbles our population. Health care workers involved in direct patient care must take precautions to prevent back strain from lifting patients and equipment; to minimize exposure to radiation and caustic chemicals; and to guard against infectious diseases, such as AIDS, tuberculosis, and hepatitis. Home care personnel who make house calls are exposed to the possibility of being injured in highway accidents, all types of overexertion when assisting patients, and falls inside and outside homes [3].

\section{Prevention through Design}

The Harvard Medical Practice Study estimated that two thirds of adverse events involving patients are caused by errors in treatment that are attributable to the systems and environment in which health care takes place and which therefore could potentially be prevented [4]. The National Institute for Occupational Safety and Health (NIOSH) recognized that companies that have implemented Prevention through Design programs experience the lowest injury rates and lower costs related to less severe injuries. NIOSH formed a national initiative on Prevention through Design in 2007 to apply these concepts broadly throughout 


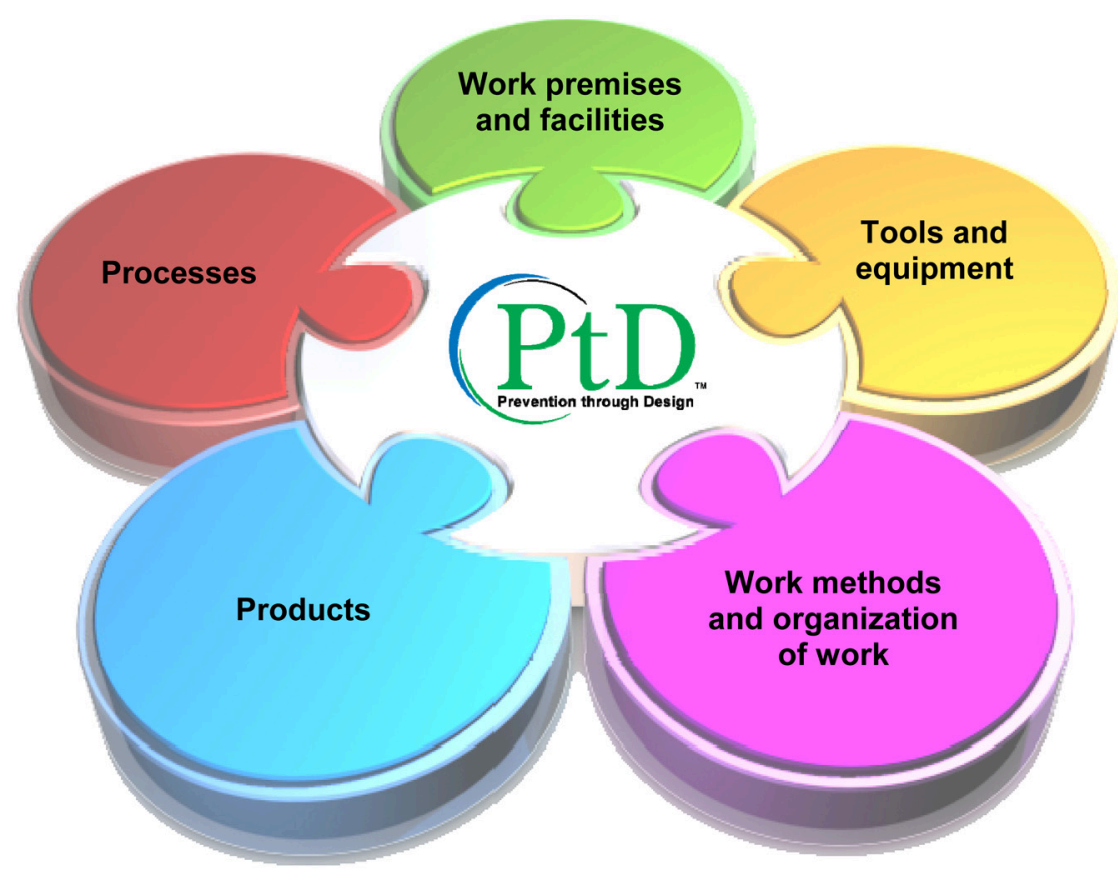

Figure 1: Prevention through Design's mission.

eight market sectors within seven years, an ambitious goal. NIOSH solicited the help of non-governmental organizations, industry and insurance representatives and academia to develop processes, products, tools and equipment, work methods and organization of work facilities to support these concepts (figure 1).

Prevention through Design is based on the hierarchy of controls (figure 2): by focusing on hazard elimination and substitution of less hazardous materials, processes, operations or equipment, followed by risk management and engineering controls and then to administrative controls and warning systems, industry can make the unsafe act difficult to do and the safe thing the obvious choice.

The business value of Prevention through Design does not end with lower rates and less costly injuries; other business efficiencies can be gained by designing the work place using these concepts. The American Industrial Hygiene Association published a study on "Demonstrating the Business Value of Industrial Hygiene" that concludes that businesses that adopt hazard control measures further up in the hierarchy of controls realize gains in faster time to market, improved operational efficiency, improved employee morale, decreased employee absenteeism (and "presentism" - where workers come to work but are not productive), reduced turnover rates, higher product quality, and increased market share [5]. 


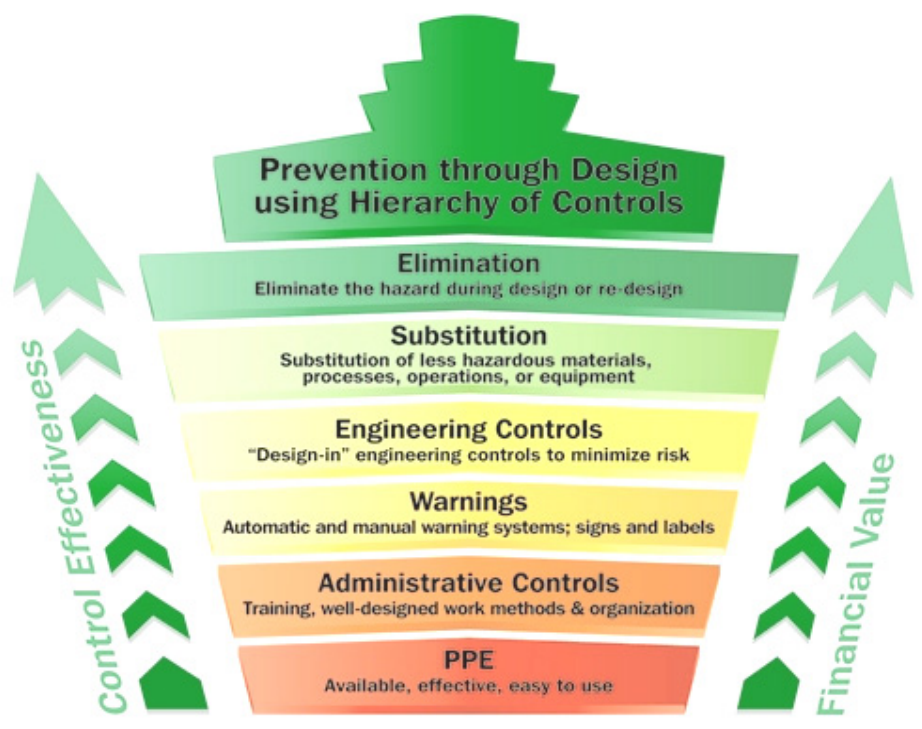

Figure 2: The hierarchy of controls.

Prevention through Design also lays the ground work for achieving sustainability and improving patient safety: if Prevention through Design concepts are followed, then operational and maintenance requirements are also factored into the design. When maintenance activities are considered and incorporated during design and optimized over the lifetime of the building, sustainable benefits ensue. By far the biggest cost of running a business is paying for the people who work in the buildings that house the business, followed by the utilities and energy demands of the buildings themselves. And in health care if the patient is put at the center of the design, less pressure is put on the health care worker to provide quality care despite their surroundings because they are not fighting, short-cutting, or otherwise working around systems and processes that don't serve the patient.

When NIOSH convened the first public workshop on Prevention through Design in July 2007 to obtain stakeholder input and engagement in developing a strategic plan for the nation, those ideas were filtered through the lenses of research, education, practice, policy and small business. Based on the deliberations of the stakeholders a strategic plan was developed and each of the eight market sectors assigned task force members to a Prevention through Design Council who will be actively involved in developing and coordinating implementation of the strategic plan. NIOSH serves as the secretariat of the Council. The input of the market sector task forces has been published in the Journal of Safety Research and this and other rapporteur reports and meeting 
proceedings can be obtained from the NIOSH Prevention through Design website (http://www.cdc.gov/niosh/topics/ptd/) [6].

\subsection{Research}

The research focus of the strategic goals addresses design factors that effectively reduce occupational morbidity, mortality, and injury; metrics that assess the impact of these design factors; methods that diffuse effective designs into general practice; and economic and business issues, including financial analysis of the impact of Prevention through Design on the business process. For the health care sector this means linking research activities to those being conducted for evidence-based designs in patient safety and high performance buildings as well as general safety research. Current NIOSH-led research activities include a benchmarking study comparing management practices related to Prevention through Design in the United States and the United Kingdom. Other work, like the Center for Health Design's Pebble Project and their recent publication, $A n$ Introduction to Evidence-Based Design, seek to quantify the benefit to patients, staff and the environment through measurement of metrics aimed at strategies that result in desired outcomes [7]. At Kaiser Permanente, the largest and oldest not-for-profit integrated health care delivery system in the United States, research using Prevention through Design concepts is most prevalent in our patient safety work at the Sidney R. Garfield Center for Innovation. This living laboratory allows clinicians to interact with full-scale mock ups of specific clinical environments and equipment, as well as with simulators, (such as with sigmoidoscopy or trauma), and with virtual environments through the use of three-dimensional role playing games.

\subsection{Education}

The education focus of the strategic goals concern motivating and equipping professional communities to continually increase their knowledge of design features that have positive impact on worker safety and health. Acquisition of Prevention through Design knowledge and skills will occur through enhanced design and engineering curricula as well as through improved professional accreditation programs that value Prevention through Design issues and include them in their competency assessments. Making business leaders aware of the potential for increasing company profitability by incorporating Prevention through Design methods into their systems and processes is also an important component of the education goal. NIOSH has sent letters to the Deans of Engineering schools to solicit their support of including Prevention through Design concepts in existing curricula. Further, some engineering educators, such as in the University of Massachusetts at Lowell Department of Work Environment, are now advocating revision of curricula so that the time for Prevention through Design is at hand. They have courses that target the full life cycle of a process or product so that occupational safety and health concepts are considered in depth during the design and manufacturing phase as well as when the process or product is introduced into the work place. And they recently 
published a study on how to implement more environmentally-sound, healthier and safer design alternatives in health care [8].

\subsection{Practice}

Practice goals focus on identifying and sharing successful procedures, processes, equipment, tools and results through on-line databases and other media. Practice also includes demonstrating the value of including worker health and safety in design decisions and exploring links with the movements toward green and sustainable design and patient safety. Sustainable design enhances indoor environmental quality, increases daylight and views, reduces noise, increases occupant satisfaction and optimizes building performance. Kaiser Permanente's High Performance Building Committee has considered and undertaken a number of projects related to sustainability that can also be applied to the prevention of occupational injuries and illnesses in health care, from the challenges related to construction safety, to worker and ultimately to patient safety. One example that illustrates how a product that was picked primarily for its environmental attributes led to worker and patient benefits as well, is cotton bat insulation, which replaces traditional formaldehyde-treated fiberglass bat insulation. Even formaldehyde-free fiberglass bat insulation is very irritating to the skin and at high enough levels (like say, during installation) may lead to cancer. Installers must wear impervious coveralls, respirators and safety glasses to prevent exposure. On the other hand cotton bat insulation requires no personal protective equipment to install, is just as easy to install, gives better insulating R-values from the same thickness as fiberglass bat insulation, and is also mold/mildew and pest resistant because of the non-toxic borate fire treatment. The benefit realized is not only in energy savings because of superior insulating properties, but superior noise reduction (three to five decibels) over tradition bat insulation also benefits staff and patients.

\subsection{Policy}

Policy strategy focuses on creating demand for safe designs for workers and incorporating these safety and health considerations into guidance, regulations, recommendations, operating procedures, and standards. The American Society of Safety Engineers is seeking to establish a standard on Safety by Design in partnership with the American National Standards Institute (ANSI). ANSI has already produced a standard on integrated building design that supports the building industry in the practice of integrative design and is related to Prevention through Design principles. The purpose of Integrative Design is to effectively manage the optimization of complex systems while pursuing sustainable practices in design and construction [9]. In addition, businesses such as Kaiser Permanente have provided testimony to the United States legislature asking for changes to regulations governing chemicals in commerce that would allow U.S. businesses to have access to detailed information on the hazards of the chemicals and products they purchase in order to make good risk management decisions and specify the safest products and chemicals for their operations. 


\subsection{Small business}

Small businesses have different operational considerations than larger businesses because their access to resources and leverage in the market place is usually restricted. Their needs with regard to Prevention through Design focus on access to resources that address their special needs and constraints.

\section{Summary}

The Prevention through Design Plan is extensive and complex. The steps that an organization must take to integrate Prevention through Design into their business process are illustrated in figure 3. These steps assisted the Prevention through Design Council in organizing the time frames for the activities needed to accomplish the goals in order that resources needed by organizations are available. For example, the first step in moving an organization toward Prevention through Design is to create awareness about its benefits. Therefore resources that support the need to create awareness of the benefits of Prevention through Design in each industry sector are critical to the success of the initiative and should be developed first. Prevention through Design is intended to be wholly integrated into the fabric of process thinking and risk management, not something that is layered on top. It will become part of the way we think about designing processes and products, building buildings and developing public policy.

\section{Stages of Adoption}

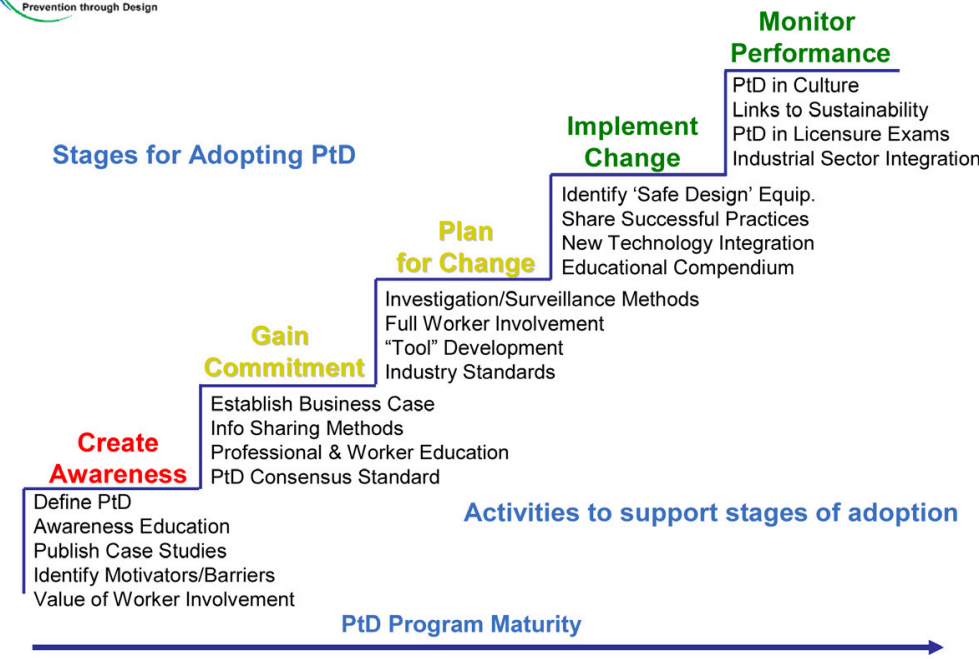

Figure 3: $\quad$ Prevention through Design stages of adoption. 


\section{References}

[1] United States Bureau of Labor Statistics. Injuries, Illness and Fatalities web site: Industry Injury and Illness Data, http://www.bls.gov/iif/oshwc/ osh/os/osnr0030.txt

[2] California Board of Certified Registered Nursing, 2006 Survey of Registered Nurses, 2007.

[3] Bureau of Labor Statistics, U.S. Department of Labor, Career Guide to Industries, 2008-09 Edition, Health Care, on the Internet at http://www.bls.gov/oco/cg/cgs035.htm

[4] Brennan, TA, Leape, LL, Laird, NM, Hebert, L, Localio, AR, Lawthers, AG, Newhouse, JP, Weiler, PC \& Hiatt, HH, Incidence of adverse events and negligence in hospitalized patients. Results of the Harvard Medical Practice Study I. New England Journal of Medicine, 324(6), pp. 370-376, 1991.

[5] American Industrial Hygiene Association, Demonstrating the Business Value of Industrial Hygiene. Synergist, 19(6), pp. 47-51, 2008.

[6] Braun, TW, Prevention through Design (PtD) from the Insurance Perspective. Journal of Safety Research, 39(2), pp. 137-139, 2008.

[7] Center for Health Design, An Introduction to Evidence-Based Design, Mid Atlantic Printers Limited, Altavista, Virginia, 2008. (http://www.healthdesign.org/research/pebble/)

[8] Quinn MM, Fuller, TP, Bello A, Galligan C, Pollution PreventionOccupational Health and Safety in Hospitals: Alternatives and Interventions. Journal of Occupational and Environmental Hygiene, 3(3), pp. 182-193, 2006.

[9] American National Standards Institute, ANSI/MTS 1.0: Whole Systems Integrated Process Guide (WSIP) for Sustainable Buildings \& Communities, 2007. 